\title{
Mechanical Properties of Powder Injection Molded
}

\section{Ni-Based Superalloys}

\author{
H. Ozkan Gulsoy ${ }^{1,2}$, Sunullah Ozbek ${ }^{2, a}$, Volkan Gunay ${ }^{2, b}$, Tarık Baykara ${ }^{2, c}$ \\ ${ }^{1}$ Marmara University, Technical Education Faculty, Göztepe, Istanbul, 34722, Turkey \\ ${ }^{2}$ TUBITAK MRC, Materials Institute, Gebze - Kocaeli, 41470, Turkey \\ Ozkan.Gulsoy@mam.gov.tr ${ }^{1,2}$, Sunullah.Ozbek@mam.gov.tr 2 ,a \\ Volkan.Gunay@mam.gov.tr ${ }^{2, b}$, Tarik.Baykara@mam.gov.tr ${ }^{2, c}$
}

Key words: Powder Metallurgy, Powder Injection Moulding, Sintering,

\begin{abstract}
This paper describes the microstructural and mechanical properties of powder injection moulded (PIM) Ni based superalloys. Ni-based superalloys were mixed with a polymeric binder (paraffin wax, carnauba wax, stearic acid and PP) and injection moulded as standard tensile bars. The critical powder loading for injection moulding were 62.5 vol. \% for standard samples. Binder removal, debinding, was performed using a two-step solvent/thermal method. After debinding the samples were sintered at $1100^{\circ} \mathrm{C}$ and at $1285^{\circ} \mathrm{C}$ under high level vacuum. Metallographic studies were conducted to reveal the extent of densification and the corresponding microstructural changes. $\mathrm{Ni}$ 718, Ni 625 and Nimonic90 samples achieved high sintered densities via supersolidus liquid phase sintering. The mechanical properties of $\mathrm{Ni} 718$, Ni 625 and Nimonic90 are determined and compared with the properties of previously reported studies on similar PIM materials.
\end{abstract}

\section{Introduction}

Powder injection moulding is a powder metallurgy process currently used for the production of complicated and near-net-shape parts of high performance materials. This technique basically combines the advantages of the plastic injection moulding with the versatility of the traditional powder metallurgy, producing highly complex part of small size, tight tolerance, and low production cost. The process overcomes the shape limitation of traditional powder compaction, the cost of machining, the productivity limits of isostatic pressing and slip casting, and the defect and tolerance limitations of conventional casting. Mechanical properties of a well-processed powder injection moulded material are indistinguishable from cast and wrought material. The PIM process is composed of four sequential steps; mixing of the powder and organic binder, injection moulding, debinding (binder removal), and sintering. If it is necessary, secondary operations such as heat and surface treatments after sintering can be performed [1-3].

The superalloys are a class of heat-resisting alloys based on nickel, nickel-iron, or cobalt that exhibit a combination of strength and resistance to surface degradation at both elevated and cryogenic temperatures. These properties make them useful for many applications in the aerospace, automotive, medical, chemical, and petrochemical industries, but their high strength and toughness make them difficult to shape via machining or forging [4]. Investment casting is often used to process superalloys, but can be costly. An alternative process is powder injection moulding, which enables complex geometry designs, minimum material loss, quick scale-up response time, and significant cost savings on moderate or large production volumes. Current use of PIM superalloys is limited partially due to scarce mechanical properties data [5-12].

This present work was aimed to investigate the comparison of sintering behaviour and mechanical properties of powder injection moulded gas atomized Ni 718, Ni 625 and Nimonic90 superalloys powders. Metallographic techniques were employed to sintered tensile bars to investigate the sintering behaviours. Densities and mechanical properties of the sintered samples were evaluated. 


\section{Experimental procedures}

The powder chemical properties and characteristics of gas atomized Ni 718, Ni 625 and Nimonic90 superalloys powders used in this study are given Table 1 and 2. Particle size distributions were determined on Malvern Mastersizer equipment and given in Fig. 1; indicate similar median particle sizes for three type powders. Morphology of the powders, observed using scanning electron microscopy are given Fig. 2(a), (b) and (c). The gas atomized powders are spherical in shape.

Table 1. Chemical composition of superalloys powders

\begin{tabular}{llllllllllll}
\hline & Ni & Cr & Fe & Nb & Mo & Al & Ti & Co & C & Si & Mn \\
\hline Ni 718 & Bal. & $17-20$ & $14-$ & $4.7-5.5$ & $2.8-3.3$ & $0.2-0.8$ & $0.6-1.1$ & -- & $0.03-$ & 0.22 & -- \\
& & & 16 & & & & & & 0.06 & & \\
Ni 625 & Bal. & $20-23$ & 5 & $3.15-4.15$ & $8-10$ & 0.4 & 0.4 & -- & 0.1 & -- & -- \\
Nimonic90 & Bal. & $18-20$ & 1.5 & -- & -- & $0.8-2$ & $1.8-3$ & $15-21$ & 0.13 & 1 & 1 \\
\hline
\end{tabular}

Table 2. Powder characteristics of superalloys powders

\begin{tabular}{clll}
\hline Item & Ni 718 & Ni 625 & Nimonic90 \\
\hline Vendor & $\begin{array}{l}\text { Osprey } \\
\text { Gas atomized } \\
\text { Spherical }\end{array}$ & $\begin{array}{l}\text { Osprey } \\
\text { Gas atomized } \\
\text { Spherical }\end{array}$ & $\begin{array}{l}\text { Osprey } \\
\text { Gas atomized } \\
\text { Spherical }\end{array}$ \\
$\begin{array}{c}\text { Shape } \\
\text { Particle size }(\mu \mathrm{m})\end{array}$ & 4.5 & 3.7 & \\
$\mathrm{D}_{10}$ & 11.9 & 11.1 & 4.1 \\
$\mathrm{D}_{50}$ & 26.2 & 26.7 & 11.0 \\
$\mathrm{D}_{90}$ & 4.9 & 5.3 & 24.7 \\
Tap density, $\mathrm{g} / \mathrm{cm}^{3}$ & 8.20 & 8.42 & 5.0 \\
Pycnometer density, $\mathrm{g} / \mathrm{cm}^{3}$ & & & 8.26 \\
\hline
\end{tabular}

A multiple-component binder system consisting of paraffin wax (PW), polypropylene (PP), carnauba wax $(\mathrm{CW})$, and stearic acid (SA) was used. Feedstock was prepared at $175^{\circ} \mathrm{C}$ with the binder melted first and then powder added incrementally. The powder loading in this mixture was 62.5 vol\%. After cooling, the feedstock was pelletised by hand. The feedstock was then injected in to a $12.5 \mathrm{MPa}$ capacity specially made injection moulding machine to produce tensile test specimens (MPIF 50). The melt temperature was $175^{\circ} \mathrm{C}$, the mould temperature was kept at $35^{\circ} \mathrm{C}$ and cycle time was 20 seconds.

Debinding was conducted in a two-step solvent/thermal operation. Green parts were first solvent debinded at $60^{\circ} \mathrm{C}$ for $4 \mathrm{~h}$ in heptane, followed by thermal debinding step using slow heating rate to $600^{\circ} \mathrm{C}$ and kept there for $1 \mathrm{~h}$. After the binder was removed, sample were pre-sintered at $900^{\circ} \mathrm{C}$ with a heating rate of $4^{\circ} \mathrm{C} / \mathrm{min}$ and kept at the final temperature for $1 \mathrm{~h}$ under vacuum. The final sintering cycle applied to the samples was as follows; samples were heated to $1100^{\circ} \mathrm{C}$ at a rate of $10^{\circ} \mathrm{C} / \mathrm{min}$ and held at $1100{ }^{\circ} \mathrm{C}$ for $5 \mathrm{~min}$., then the samples were heated to sintering temperatures of $1285^{\circ} \mathrm{C}$ at a rate of $10^{\circ} \mathrm{C} / \mathrm{min}$ and they were held at sintering temperature for 2 hours under high vacuum level $\left(10^{-4} \mathrm{~Pa}\right)$. Sintering of all samples was performed within an atmosphere-controlled high temperature vacuum furnace of Protherm Co. After sintering, Ni 718 samples were solution heat treated at $980^{\circ} \mathrm{C}$ for 1 hour in vacuum and air cooled to room temperature. Then they were aged at $720^{\circ} \mathrm{C}$ in air for 8 hours, furnace cooled to $620^{\circ} \mathrm{C}$, aged in air for 8 hours, and oil quenched. Sintered Ni 625 samples were also solution heat treated at $1150^{\circ} \mathrm{C}$ for 2 hours and then oil quenched. Sintered Nimonic 90 samples were solution heat treated at $1080^{\circ} \mathrm{C}$ for 1 hour and then aged at $700^{\circ} \mathrm{C}$ for 16 hours. 


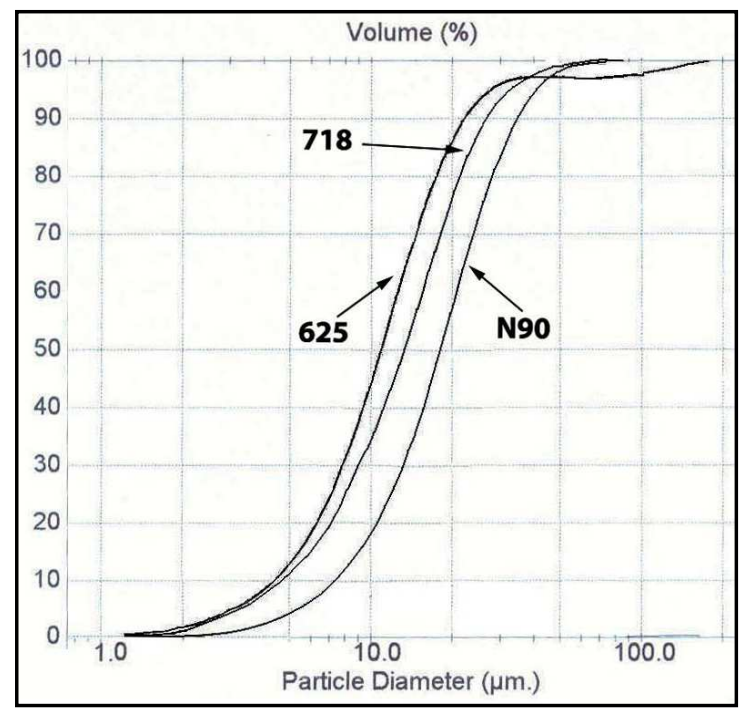

Fig.1. Cumulative particle size distributions for superalloy powders studied.

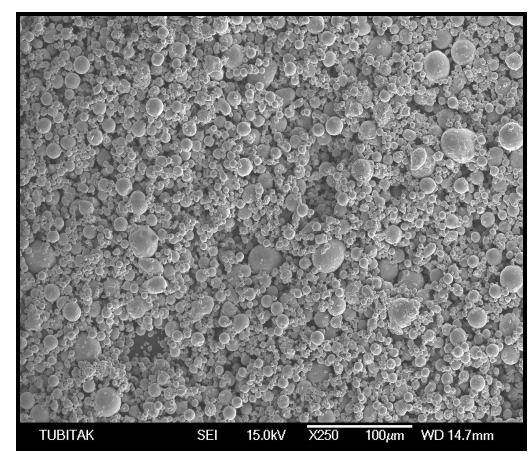

(a)

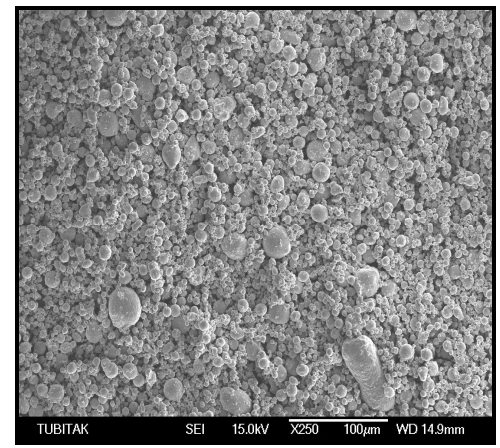

(b)

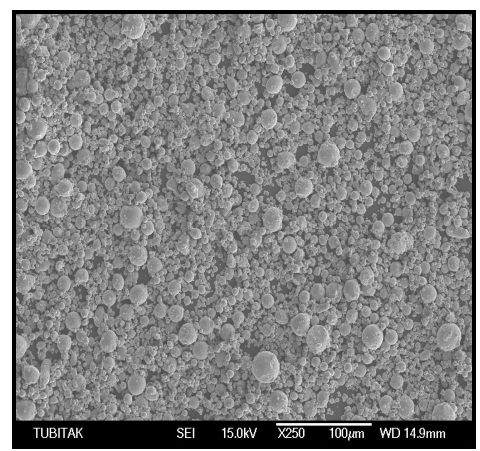

(c)

Fig.2. Scanning electron micrograph of superalloy powders (a) Ni 718 (b) Ni 625 and (c) Nimonic90

The densities of the sintered samples were measured by means of the Archimedes water-immersion method. For metallographic examination, samples were cut from the centre of the each sintered tensile test bar. All tensile tests were performed using Zwick 2010 mechanical tester at a constant crosshead speed of $1 \mathrm{~mm} / \mathrm{min}$ (25 mm gauge length). The hardness tests were performed using an Instron-Wolpert Dia Testor 7551 at HRC scale. At least three samples were tested under the same conditions to guarantee the reliability of the results.

\section{Results and Discussion}

Fig. 3 shows the results of measured relative density of $\mathrm{Ni} 718$, Ni 625 and Nimonic90 superalloy samples sintered at $1285^{\circ} \mathrm{C}$ for 2 hours, with an attained maximum relative density of $97.81 \%$, $99.18 \%$ and $98.13 \%$, respectively. The relative densities of all samples were increased at high sintering temperature. The highest relative density values were found from Ni 625 samples and the lowest relative density values were obtained from the samples of $\mathrm{Ni} 718$. 


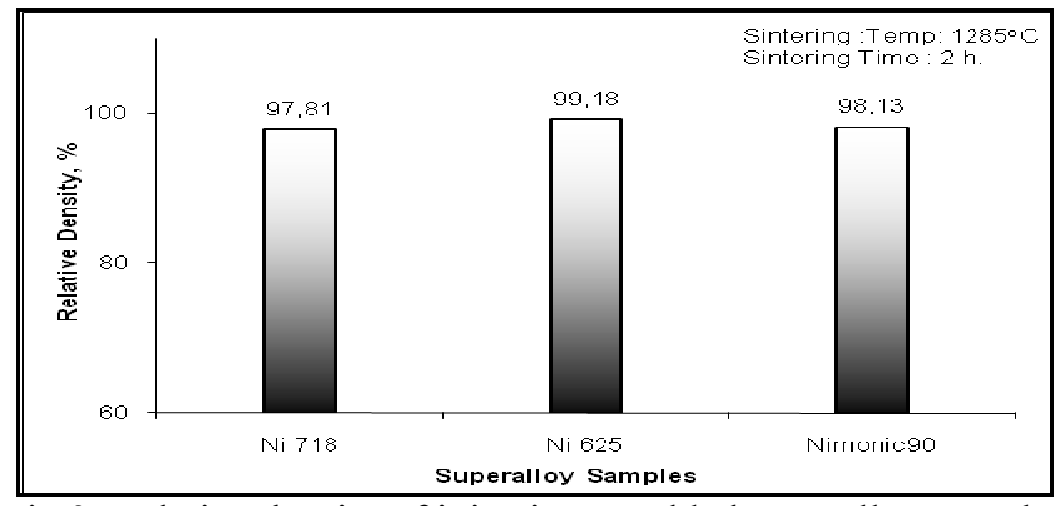

Fig.3. Relative density of injection moulded superalloy samples

Microstructures of injection moulded superalloy samples are shown in Fig. 4. Micrograph of sintered samples of Ni 625 powders in Fig.4 (b) do not show pores in the grain boundaries though some porosity is apparent inside the grains. This is indicating that why the high relative density of sintering was obtained. On the other hand relatively high porosity concentration is clearly seen on the grain boundaries of samples produced from Ni 718 powder, as shown in Fig.4 (a). It could be seen clearly from these micrographs that higher pore contents and the accumulation of pores along the grain boundaries hindered the grain growth and development of higher relative density of sintered sample of $\mathrm{Ni} 718$ and of Nimonic 90 powders, especially for sintered samples of Nimonic 90 powders, as compared to sintered samples of $\mathrm{Ni} 625$ powders. However, at this sintering temperature $\left(1285^{\circ} \mathrm{C}\right)$, active mechanism is super liquid phase sintering for all superalloy powder materials used in this study, but it seems this sintering temperature is more effective for Ni 625 powder and this led to very high sintered density. It should be also noted that some of the black spots are seemed to be oxides formed on the former grain boundary surfaces. The nature of the oxides is not studied in this work to make any statements here and therefore further studies are required. According to microstructures and relative density values, It could be suggested that Ni 718 and of Nimonic90 powders may be sintered at higher temperatures for further increase in densities.

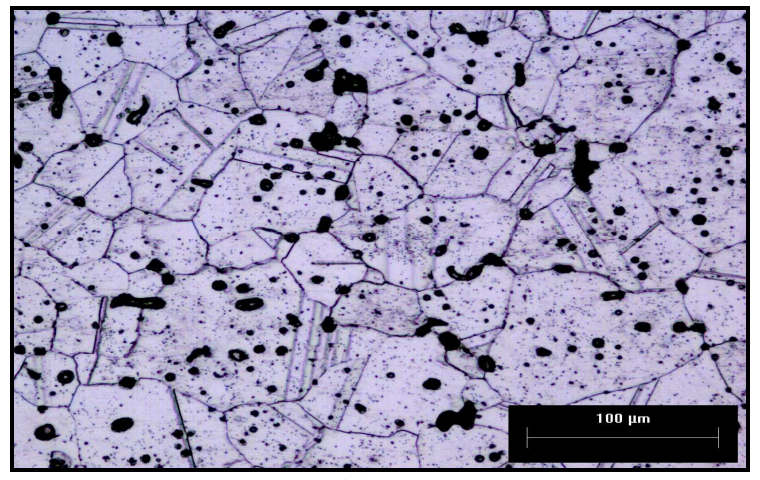

(a)

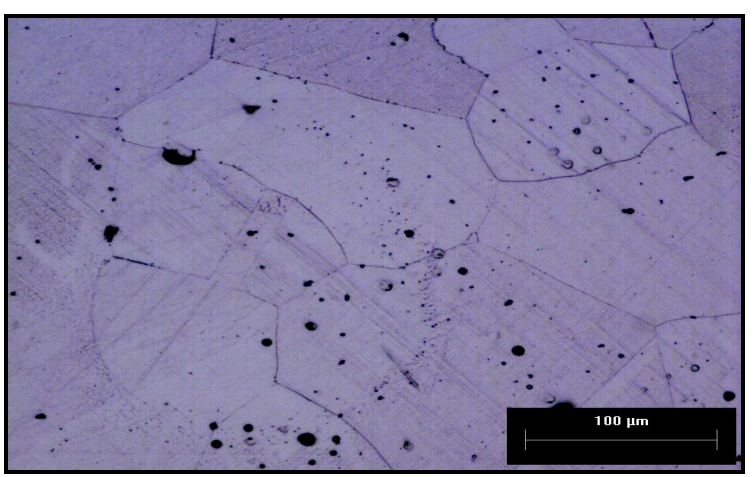

(b)

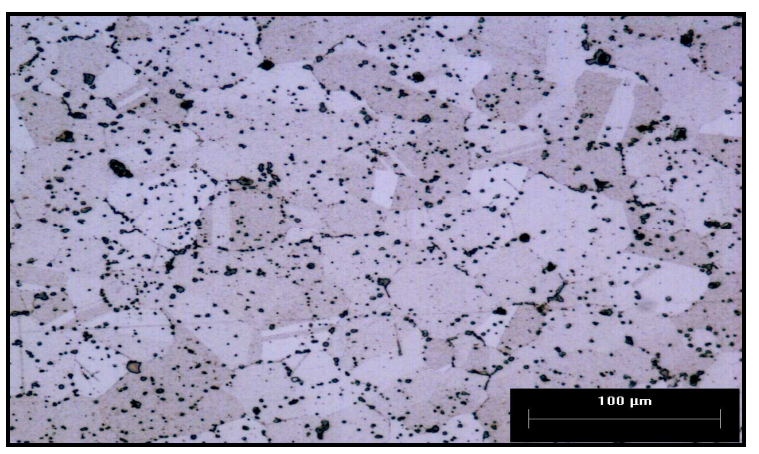

(c)

Fig.4. Microstructure of injection moulded superalloy samples (a) Ni 718 (b) Ni 625 and (c) Nimonic 90 sintered at $1285^{\circ} \mathrm{C}$ for 2 hours. 
The mechanical properties increased positively for all superalloy powder materials used in this study. Fig. 5 shows ultimate tensile strength, elongation and hardness of injection moulded superalloy samples after heat treatment. It is found that Ni 718 and Nimonic90 tensile bars have higher tensile strength than Ni 625 samples. Similarly, Ni718 and Nimonic90 samples have higher hardness than Ni 625 samples. High hardness values found for Ni 718 and Nimonic90 powder samples might have been caused by the oxide particle available within the structure, mostly seen on the grain boundaries. Higher ductility is achieved with Ni 625 samples as compared to Ni 718 and Nimonic90 samples. These moderate mechanical properties are well agreed with properties found with same materials produced with PIM in literature $[5,6,7,12]$. But, when these results are compared with casting and forging superalloy products the properties of the present study is producing values within the lower level of properties of the other techniques $[4,5,7,12]$.

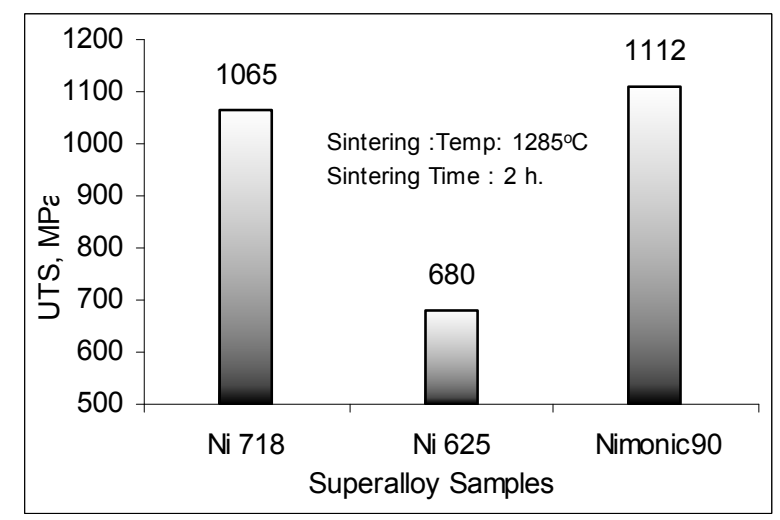

(a)

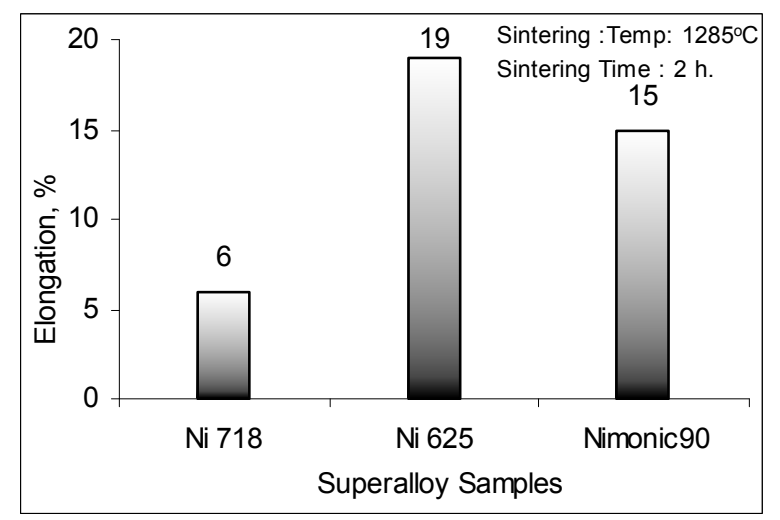

(b)

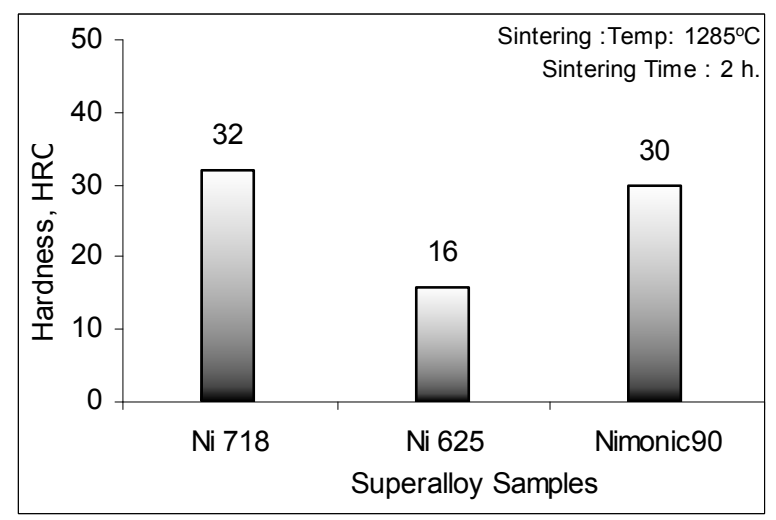

(c)

Fig.5. Mechanical properties of injection moulded superalloy samples -heat treated-, (a) tensile strength, (b) elongation, (c) hardness 


\section{Conclusions}

From the results obtained of the present investigation; the following conclusions can be drawn.

1. It is shown that the $\mathrm{Ni}$ based gas atomised powders of superalloys ( $\mathrm{Ni} 718, \mathrm{Ni} 625$ and Nimonic90) (62.5\% solid loading) could be sintered to $97.8-99.1 \%$ of relative density at $1285^{\circ} \mathrm{C}$ for 2 hours under high level vacuum.

2. It is also shown that mechanical properties of gas atomized superalloy samples (Ni 718, Ni 625 and Nimonic 90) have 680-1112 MPa tensile strength, 6-19\% elongation and 30-32 HRC hardness values.

3. When the results produced in this study compare with casting and forging of the same superalloy products, PIM superalloy products have lower mechanical values but these parts can be easily used for all non-critical applications.

\section{Acknowledgements}

This work has been supported by the Scientific Research Project Programme of Marmara University (Project No. FEN-C-YLP-181208-0284). The authors are grateful to Marmara University and Sandvik Ospray Ltd. for their financial support and the provision of laboratory facilities.

\section{References}

1. R.M. German and A. Bose, in: Injection molding of metals and ceramics, Princeton, NJ, Metal Powder Industries Federation (1997).

2. R.M. German, in: Powder injection molding, Princeton, NJ, MPIF (1990).

3. H.O. Gulsoy, S. Ozbek and T. Baykara: Powder Metall. 2007, 50, (2), p. 120.

4. ASM Specialty Handbook: Nickel, Cobalt, and Their Alloys, compiled by J.R. Davis, ASM International, Materials Park, OH. (2000).

5. J.C.LaSalle, B. Sherman, C. Scott, K. Bartone, R. Bellows and D. Lowery, in: Advances in Powder Metallurgy \& Particulate Materials, compiled by C.L. Rose and M.H. Thibodeau, MPIF, Princeton, NJ, (1999), p 6.39

6. B. Holmes, P. Hatfield and B. Sherman, in: Advances in Powder Metallurgy and Particulate Materials, compiled by C.L. Rose and M.H. Thibodeau, MPIF, Princeton, NJ, (1999), p. 6.82

7. J.J. Valencia, T. McCabe, K. Hens, J.O. Hansen and A. Bose, in: Conference on Superalloys 718, 625, 706, and Various Derivatives, compiled by E.A. Loria, TMS, Pittsburgh, PA, (1994), p.935

8. A. Bose, R. Schmees, J.J. Valencia and J. Spirko, in: Advances in Powder Metallurgy and Particulate Materials, compiled by R.A. McKotch and R. Webb, MPIF, Princeton, NJ, (1997), p. 18.99

9. K.F. Hens, J.A. Grohowski, R.M. German, J.J. Valencia and T. McCabe, in: Advances in Powder Metallurgy \& Particulate Materials, compiled by C. Lall and A.J. Neupaver, MPIF, Princeton, NJ, (1994), Vol 4, p. 137

10. J.M. Contreras, A.J. Morales and J.M. Torralba: Powder Metallurgy, 2008 Vol 51 No 2, p. 103

11. B.N. Nobrega1, W. Ristow and R. Machado: Powder Metallurgy, 2008 Vol 51 No 2, p. 107

12. J. Johnson, L.K. Tan, P. Suri and R.M. German, in: PIM Compilation III: Secondary Processing and Material Properties, Metal Powder Industries Federation, Denver, CO. (2007), vol 4, p.89 